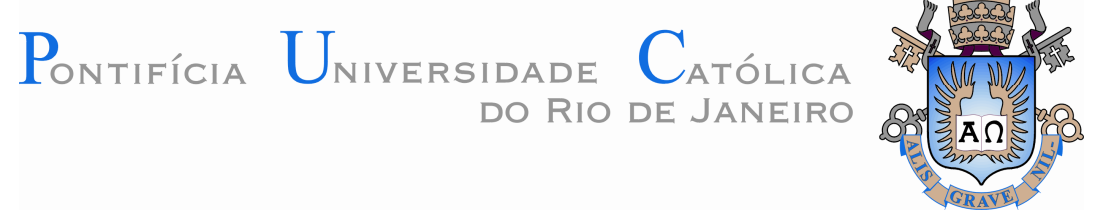

Ana Neuza Botelho Videla

\title{
Emprego da Solda a Laser na Criação e \\ Produção de Joias
}

Dissertação de Mestrado

Dissertação apresentada como requisito parcial para obtenção do título de Mestre pelo Programa de Pós-Graduação em Design da PUC-Rio.

Orientador: Claudio Freitas de Magalhães

Rio de Janeiro

Agosto de 2009 


\section{Pontifícia Universidade Católica $_{\text {a }}$

Ana Neuza Botelho Videla

\section{Emprego da Solda a Laser na Criação e \\ Produção de Joias}

Dissertação apresentada como requisito parcial para obtenção do título de Mestre pelo Programa de PósGraduação em Design da PUC-Rio. Aprovada pela Comissão Examinadora abaixo assinada.

Claudio Freitas de Magalhães

Orientador

Departamento de Artes \& Design - PUC-Rio

Jorge dos Santos Lopes

INT

Rejane Spitz

Departamento de Artes \& Design - PUC-Rio

Prof. Paulo Fernando Carneiro de Andrade

Coordenador Setorial do Centro

Teologia e Ciências Humanas - PUC-Rio

Rio de Janeiro, 27 de agosto de 2009 
Todos os direitos reservados. É proibida a reprodução total ou parcial do trabalho sem autorização da universidade, da autora e do orientador.

\section{Ana Neuza Botelho Videla}

Coordenadora da Escola de Joalheria - SENAI-RJ. Graduação em Ciências Sociais - UFF, 1986. Formação em joalheria nas Escolas Ar.Co, 1995 e Contacto Directo, 1996 - 1998 em Lisboa - Portugal.

Ficha Catalográfica

Videla, Ana Neuza Botelho

Emprego da solda a laser na criação e produção de joias / Ana Neuza Botelho Videla; orientador: Cláudio Freitas de Magalhães. - Rio de Janeiro: PUC, Departamento de Artes \& Design, 2009.

135 f.: il; $29,7 \mathrm{~cm}$

Dissertação apresentada como requisito parcial para obtenção do grau de Mestre pelo Programa de Pós-graduação em Design do Departamento de Artes \& Design de PUC-Rio. Aprovado pela comissão Examinadora abaixo assinada.

Incluí referências bibliográficas.

1. Artes - Teses. 2. Design de jóias. 3. Inovação. 4. Tecnologia de Solda a Laser. I. Magalhães, Cláudio Freitas de. II. Pontifícia Universidade Católica do Rio de Janeiro. Departamento de Artes \& Design. III. Título 


\section{Agradecimentos}

Agradeço ao meu orientador, Prof. Claudio Magalhães, pela oportunidade e confiança no meu trabalho.

Agradeço aos funcionários do Departamento de Artes \& Design pela gentileza no atendimento.

Agradeço a toda equipe do SENAI-RJ, através do meu gerente Bernardo Schlaepfer, a compreensão e incentivo à conclusão da minha pesquisa.

Agradeço a toda equipe do Projeto Inotec, Ida, Cidda, Julia, Armando, Werner, Rudolf, Jeanine, Gregório e Ana Julia, que muito contribuíram para viabilização dessa pesquisa..

Agradeço aos meus queridos amigos, Giselle, Beth, Moninha, Sol, Bia, Bira, Cecília e Kuldeep, pelas mais diversas formar de propiciar o conforto necessário nos momentos mais difíceis.

Agradeço à Adriana, Leo e Bia, meus familiares pelo apoio incondicional.

Por último, mas não menos importante, agradeço ao meu companheiro Daniel, pelo amor e apoio incessante. 


\section{Resumo}

Videla, Ana Neuza Botelho; Magalhães, Claudio Freitas de. Emprego da Solda a Laser para Criação e Produção de Joias. Rio de Janeiro, 2009. 135p. Dissertação de Mestrado - Departamento de Artes \& Design, Pontifícia Universidade Católica do Rio de Janeiro.

A tecnologia de solda a laser começa a ser muito utilizadas pelas grandes indústrias do setor joalheiro brasileiro. Entretanto, devido ao seu alto valor, é mais empregada pelas empresas de maior porte. O objetivo desta pesquisa foi verificar a influência do uso da solda a laser para promover a inovação no design, ou seja, verificar a contribuição da tecnologia para a criação e produção de jóias. Através de uma pesquisa bibliográfica, onde analisamos o design de jóias perante o conceito de inovação, e de uma pesquisa-ação - metodologia que prevê a participação da pesquisadora nos atendimentos às empresas, verificamos que o acesso à tecnologia a laser pode promover a inovação no design de jóias, aqui entendido como diferenciação na configuração, aumento de qualidade e/ou redução do tempo do processo produtivo.

\section{Palavras-chave}

Inovação; design de jóias; tecnologia e solda a laser 


\section{Abstract}

Videla, Ana Neuza Botelho; Magalhães, Claudio Freitas de (Advisor). The use of laser welding for the creation and production of jewel. Rio de Janeiro, 2009. 135p. MSc. Dissertation - Departamento de Artes, Pontifícia Universidade Católica do Rio de Janeiro.

The technology of laser welding is beginning to be widely used by large industries of the Brazilian jewelry industry. However, due to its high value, it is only used by larger companies. The objective of this research was to examine the influence of the use of laser welding to promote innovation in design, or check the contribution of technology to the creation and production of jewelry. Through a literature search, where we analyze the jewel design using the concept of innovation, and an action research - methodology that provided the researcher's participation in consultations to businesses, check if access to laser technology can promote innovation in design of jewelry, here understood as differences in configuration, high quality and / or reducing the duration of the production process.

\section{Keywords}

Innovation; jewelry design; technology and laser welding 


\section{Sumário}

1. Introdução 12

1.1 Características e Cooperação em Inovação 19

1.2 Problema 23

$\begin{array}{ll}1.3 \text { Objetivo } & 24\end{array}$

1.3.1 Objetivo Operacional $\quad 24$

$\begin{array}{ll}1.4 \text { Metodologia } & 25\end{array}$

1.4.1 Metodologia e Delineamento da Pesquisa sobre Análise de Discursos 25

1.4.1.1 Delineamento da Pesquisa 26

1.4.1.2 Técnica de Investigação $\quad 27$

1.4.2 Metodologia e Delineamento da Pesquisa do Projeto Inotec 27

2. Inovação 29

2.1 A Inovação, o Design e a Joia 31

2.1.2 A Inovação Através do Design 33

2.1.2 Contribuição do Design para o Setor Joalheiro 41

2.1.3 Utilização do Design na Indústria Joalheira 47

2.2 Transferência de Tecnologia 57

3. Novas Tecnologias para Produção de Joias 63

$\begin{array}{ll}\text { 3.1 Tecnologia da Solda a Laser } & 64\end{array}$

4. Pesquisa de Campo 83

4.1 Estudo sobre Discurso a Respeito do Design de Jóias Brasileiro 84

4.2 Levantamento das Empresas do Setor Joalheiro 99

$\begin{array}{ll}\text { 4.2.1 Pesquisa Projeto Inotec } & 101\end{array}$

4.2.1.1 Desenvolvimento da Pesquisa 102

$\begin{array}{ll}\text { 4.2.2 Análise dos Resultados } & 107\end{array}$

5. Considerações Finais 124

6. Referências Bibliográficas 129 


\section{Índice de Imagens}

Foto 1 - Giovanni Corvaja, Anel Fidelity, Ouro 750, 2008

Foto 2 - Giovanni Corvaja, Anel Ouro 750 e 800; 2001; 51

Foto 3 - Giovanni Corvaja, Bracelete Ouro 750; 1998

Foto 4 - Anel Ouro branco e diamante 750, Niessing; 1979

Foto 5 - Anel Performance, Ouro fino e platina, Niessing; 53

Foto 6 - Anel Iris Ouro fino e prata, Niessing; 1984

Foto 7 - Antonio Bernardo, Brinco Impulso, IF Design, 2007

Foto 8 - Antonio Bernardo, Colar Satélite, IF Design, 2009

Foto 9 - Paulo Martingo. Experimentos com a solda laser 2007.

Prata 925. Dimensões $40 \mathrm{~mm}$ X $30 \mathrm{~mm} \quad 70$

Foto 10 - Paulo Martingo.Experimentos com a solda laser 2007

Cobre, Latão e Esfera de Aço. Dimensões 28mm X 17mm 71

Foto 11 - John Galeano Ouro, rubi, diamante

e esmalte, 2008

Foto 12 - GEO.WIRED MOON men's, Tom Rucker,

Platina 950 e diamante branco e azul, $2007 \quad 75$

Foto 13 - CAGE.2, Tom Rucker, Platina e Safira, 2006

Foto 14 - Supernova, Tom Rucker, Platina 950

Ouro 750 e Diamantes, 2007

Foto 15 - GEO.2 Spheres, Tom Rucker, Platina,

ouro 750 e diamante, 2006

Foto 16 - David Poston, Pulseira:Well.well, well 2004,

liga de estanho

Foto 17 - David Poston, Pulseira:Cyprus 2003, tins

Foto 18 - David Poston, Pulseira: Rofin-Baasel" 2002 /

Collection of: Rofin Baasel, Ouro branco

Foto 19 - Fase de execução da peça em titânio e tecido

com impressão fotográfica. Daniel Mattos e Geanna Pollazon, 2009.

Foto 20 - Daniel Mattos e Geanna Pollazon, Visita Virtual.Titânio,

linha tecido com impressão fotográfica 2009

Foto 21 - Tobias Teigelkötter, Exemplos do site da Rofin-Baasel,

Platina 950, safira e água marinha 
Foto 22 - Tobias Teigelkötter, Exemplos do site da Rofin-Baasel,

Platina 950, safira e água marinha

Foto 23 - Lúcia Abdenur, Broche Mar de Luzes 2 lugar na

categoria"Brilliant" do American Facet Award, em Nova York

Foto 24 - Ana Paula Feijó, AngloGold Ashanti - Finalista 2008.

Buquê de Borboletas, em ouro amarelo 92

Foto 25 - Bárbara Uderzo, Aneis Blob, plástico e Ag 925,1993 96

Foto 26 - Bárbara Uderzo, Aneis Succulent, madeira,

terra e cactos, 1993

Foto 27 - Fragmento da peça do experimento com a solda a laser 116

Foto 28 - Fragmento da peça do experimento com a solda a laser 117

Foto 29 - Máquina em operação 119

Foto 30 - Concerto de caixa em prata $950 \quad 119$

Foto 31 - Experimentos da Escola de Joalheria 120 


\section{Índice de Figuras}

Figura 1 - Modelo de Inovação, Marquis and Meyers,

Successful Industrial Innovation

Figura 2 - Complexidade e os níveis em uma organização

$\begin{array}{ll}\text { para uma auditoria de design } & 38\end{array}$

Figura 3 - Princípio de funcionamento $\quad 65$

Figura 4 - Microestrutura resultante da fusão superficial de uma

chapa de aço inoxidável causada por um feixe de laser 66

Figura 5 - Junta de Brasagem $\quad 67$ 


\section{Índice de Tabelas}

Tabela 1 - Exportação Brasileiras do Setor de Gemas e

Metais Preciosos(*) 2007 / 2008

Tabela 2 Exportação Brasileiras do Setor de Gemas

e Metais Preciosos

Tabela 3 - Exportação de joalheria de metais preciosos -

$1971 / 2005$

Tabela 4 - Exportações Brasileiras (2002-2008) US\$1,00

“Toda a percepção é também pensamento, todo raciocínio é também intuição, toda observação é também invenção". Rudolf Arnheim 